\title{
MULTIPLICIDAD ESPACIAL Y REFERENCIAS SENSORIALES EN "NADA ÚTIL" DE CLARA OBLIGADO
}

\author{
Maja Zovko \\ Universidad de Zagreb \\ mzovko2@ffzg.hr
}

\begin{abstract}
Resumen: En el artículo se analizan los diferentes espacios del cuento "Nada útil", perteneciente a la colección La muerte juega a los dados (2015), de Clara Obligado, con el énfasis puesto en la oposición y la confluencia entre exterior e interior, los espacios del presente y los evocados, así como en los efectos sensoriales, sus significados y su diferenciada función. Además, se estudian los elementos de cohesión espaciales entre este cuento y el resto que integran la ya mencionada compilación, los objetos que los constituyen y la gran riqueza léxico-connotativa que confiere a este texto lirismo y fuerza sugestiva.
\end{abstract}

Palabras clave: Clara Obligado, La muerte juega a los dados, espacio, referencias sensoriales

\section{SPATIAL MULTIPLICITY AND SENSORIAL REFERENCIES IN CLARA OBLIGADO'S "NADA ÚTIL"}

\begin{abstract}
This paper analyses the different spaces in the short story "Nada útil", part of Clara Obligado's collection La muerte juega a los dados (2015), with an emphasis on the opposition and the confluence between exterior and interior, spaces of the present and the evoked ones, as well as on sensorial effects, their meanings and their differentiated function. In addition, we study the elements of spatial cohesion between this short story and the others which compose the aforementioned collection, the objects that constitute them and the great lexical-connotative richness that gives this text lyricism and suggestive force.
\end{abstract}

Keywords: Clara Obligado, La muerte juega a los dados, space, sensorial references

DOI: $\underline{\text { htps://doi.org/10.24029/lejana.2018.11.256 }}$

Recibido: el 15 de mayo de 2018

Aceptado: el 17 de agosto de 2018

Publicado: el 22 de octubre de 2018 


\section{La muerte juega a los dados: espacio literario para el mestizaje y la hibridez}

Clara Obligado, escritora argentina afincada en España desde 1976 a raíz del exilio, publicó en 2015 una colección de dieciocho relatos, titulada La muerte juega a los dados, que cuestiona distintos temas, conceptos y categorías tradicionales y plantea una escritura descolocada, fuera de los límites, extranjera (Obligado, 2015), mestiza, capaz de reunir todos los castellanos (Caballero, 2015). Concebida así, esta obra llega a ser la continuidad de una consolidada aunque no suficientemente conocida carrera de gran valor literario, en la que esta autora de diversas novelas, ${ }^{1}$ de libros de relatos $^{2}$ y ensayos ${ }^{3}$ ha abogado por la diversidad, la abolición de las fronteras y la excentricidad como condición del pensamiento (Abdala, 2016). Según Obligado, la literatura es ambigüedad en estado puro, "el espacio de la pregunta, no de las respuestas" (Abdala, 2016). Esta ambigüedad y el mestizaje se pueden observar en diferentes vertientes de su arte narrativo: en el lingüístico, por su propensión de utilizar sus dos castellanos, el que se habla en su país de acogida y el que se usa en su país natal (Obligado, 2005), o en el genérico, por la creación de libros en los que el destierro, el viaje, este ir y venir, esta espiral constituye la historia de sus cuentos (Obligado, 2011) que se desvela completamente, tal y como sugiere en El libro de los viajes equivocados, si el lector los lee "en el orden en el que aparecen, ya que esconden un texto más amplio [...]" (Obligado, 2011). Clara Obligado, en palabras de Carmen Valcárcel, “desplaza las fronteras genéricas, creando textos híbridos (microcuento/ cuento/ novela), relatos espiralados que ponen en cuestión los límites y el concepto mismo de obra literaria" (2015: 95).

En el caso de La muerte juega a los dados, se trata de una colección de relatos que comparte rasgos con la novela, ya que "proyecta una concepción del mundo en un vasto conjunto de sucesos heterogéneos", pero a la vez cada uno de sus cuentos "enfoca una visión de la vida en un suceso de intensa unidad de tono" (Anderson Imbert, 2007: 44). Esta colección, muy heterogénea en cuanto a las estrategias narrativas y temáticas abordadas, es, según la autora, un rompecabezas en el que cada cuento encaja en los demás, pero también responde a una lógica distinta: hay cuentos realistas, hay microficción, otros son relatos largos, surrealistas, y el lector, mientras lee, va armando una novela en su cabeza. ${ }^{4}$ La novela no está escrita, pero el lector se la imagina en los silencios (Lorenzón, 2016). Análogamente, al principio del libro matiza que esos "cuentos proponen al menos dos itinerarios de lectura: el primero es lineal, y en él se percibirá la trama policíaca y la historia de la familia Lejárrega; el segundo lo puede organizar el lector a voluntad, y en él parecerán historias que tienen algunos puntos en común" (Obligado, 2015).

\footnotetext{
${ }^{1}$ La hija de Marx (1996, Premio Femenino Lumen), Si un hombre vivo te hace llorar (1998), No le digas que lo quieres (2002), Salsa (2002) (Valcárcel, 2015: 93). Por su libro Petrarca para viajeros publicado en 2015 ganó el Premio Juan March Cencillo de Novela Breve (Castro, 2016).

${ }^{2}$ Una mujer en la cama y otros relatos (1990), Las otras vidas (2005), El libro de los viajes equivocados (2011, IX Premio Setenil), La muerte juega a los dados (2015). Además, ha publicado el libro de relatos colectivo titulado Sobre morpios y otros golpes (1982) y dos antologías de microcrrelatos: Por favor, sea breve 1 (2001) y Por favor, sea breve 2 (2009) (Valcárcel, 2015: 93).

${ }^{3}$ Qué me pongo (Mujeres ante la moda) (2000), Mujeres a contracorriente. (La otra mitad de la historia) (2004), ¿De qué se ríe la Gioconda? (O por qué la vida de las mujeres no está en el arte) (2006) (Valcárcel, 2015: 93).

${ }^{4}$ Según Gabriela Mora en su artículo "Notas teóricas en torno a las colecciones de cuentos integrados (a veces cíclicos)", es "el lector el que empujado por ciertos fenómenos textuales, inferirá la calidad «unitiva»o de «totalidad»" (1993: 132).
} 
Por un lado, la colección se puede leer como una novela policíaca cuyo hilo conductor es el enigma de la muerte del señor Lejárrega, narrada en el cuento inaugural "Un cadáver en la biblioteca" y retomada reiteradamente en los sucesivos cuentos. Por el otro, el conjunto de estos cuentos podría interpretarse como una saga familiar que abarca un largo lapso temporal, desde los principios del siglo pasado hasta la actualidad, y muchos escenarios interrelacionados, entre ellos, Argentina, México, Francia, Inglaterra, Polonia y España. La narración, así, no está enfocada primordialmente en la búsqueda del asesino de Héctor, sino, ante todo, en las vivencias de los demás miembros de la familia, puesto que, en palabras de Amalia, el personaje del cuento "Efecto coliflor", esposa del detective O'Brien que investiga el caso: "Al fin y al cabo, lo esencial no es quién mató a quién [...] lo importante es qué sucedió con toda esa pobre gente que se quedó viva, qué les pasó después. Lo fundamental no es la solución de los grandes enigmas, sino la vida de todos los días" (Obligado, 2015: 125).

Paralelamente, desvela Clara Obligado, "es un libro de auto ficción [sic]; que parte de vivencias personales" (Abdala, 2016). Es la historia de su madre, sus hermanas y sus tías, que ella escribe para entender mejor a su familia y a su clase social (Abdala, 2016). La hibridez no se consigue únicamente a raíz de la esfumación de las fronteras genéricas, sino también de los límites entre lo verídico y lo ficcional. Las dedicatorias, los homenajes y los agradecimientos indican el trasfondo autobiográfico, así como los rasgos que los personajes comparten con la autora. Así pues la narradora homodiegética de "Verano", de profesión escritora, en sus cartas dirigidas a su hermana melliza relata el proceso de creación de su nuevo libro, al que define como la historia de su familia convertida en cuentos (Obligado, 2015: 214), motivado por la conversación con una amiga psicóloga quien le dijo que cuando alguien iba a su consulta, en su diván se sentaban tres generaciones (219), justamente el número de generaciones retratadas en la historia familiar de los Lejárrega que empieza con el matrimonio formado entre Leonora y Héctor, atraviesa la vida de su única hija Alma que, por su parte, ha tenido tres hijas: Sonia, que desaparece víctima de la dictadura, y las mellizas. Otra rama familiar está representada por Diego Lejárrega, hermano de Héctor, y su mujer, Liza. Fruto de esta unión es Fernanda, casada con Raymond y más tarde en una relación con su primer amor, Bruno. El periplo vital de estos personajes es seguido a lo largo de diferentes cuentos elaborados como autosuficientes.

Se trata, por tanto, de una colección que "presenta paradigmas de relación entre los diversos relatos que componen un volumen" (Mora, 1993: 131) siendo las colecciones de relatos interrelacionados, en denominación de Mora, series o colecciones integradas (136). ${ }^{5}$ Estas colecciones, sintetiza José Adalberto Sánchez Carbó, "participan de la estética de la fragmentación retomando algunas características de la estética de la totalidad. Si bien los cuentos son obras cerradas también son considerados como parte de un todo, hipotético" (Sánchez Carbó, 2009: 40). Concebir de esta forma el libro de Clara Obligado permite un acercamiento más totalizador a algunos de los temas que se plantean: el exilio y las migraciones, la desmembración de una clase social, las guerras y sus secuelas, las dictaduras, el destino humano y el azar, entre muchos otros. Los nexos de cohesión entre estos cuentos son de lo más diversos. Los personajes secundarios de un cuento se convierten en los

\footnotetext{
${ }^{5}$ Sobre la terminología de las colecciones de cuentos integrados, ver los artículos de Gabriela Mora (1993), Francisca Noguerol Jiménez (2008), Graciela Tomassini (2004), Miguel Gomes (2000) y la tesis doctoral de José Adalberto Sánchez Carbó (2009).
} 
principales de otro. Asimismo, se repiten y se completan múltiples referencias literarias, a obras de Agatha Christie ("Un cadáver en la biblioteca", "El efecto coliflor"), Margaret Mitchell y Lo que se llevó el viento ("Un cadáver en la biblioteca", "El efecto coliflor", "La huida" y "Verano") y Marcel Proust ("La peste", "Verano"), entre muchas otras. Los elementos de integración pueden tener que ver también con la reflexión sobre el azar, las coincidencias, la historia que esconden los objetos o los espacios que serán el tema de este análisis a través del cuento "Nada útil".

\section{La pluralidad de espacios en "Nada útil"}

El sexto cuento de la colección, "Nada útil", está ubicado en París, durante la Segunda Guerra Mundial, identificación permitida a través de la presencia de los alemanes y la policía francesa (Obligado, 2015: 78), así como la persecución del personaje principal bajo la acusación de un vecino que seguramente es judío (81). También es posible determinar la ubicación espacial y temporal gracias a los elementos de cohesión que construyen a manera de una totalidad La muerte juega a los dados, tal y como se verá más adelante. El cuento no se comunica únicamente con los demás que integran la colección, sino también con Infancia en Berlín hacia el mil novecientos de Walter Benjamin, más en concreto con "Caza de mariposas", del cual se cita un fragmento en el epígrafe: "En medio de tanta destrucción, turbación y violencia, en un pliegue de la red, temblando y sin embargo llena de gracia, resistía la mariposa aterrorizada" (71). La particularidad de estos episodios de la infancia de Walter Benjamin rememorados literariamente, según Anja Lemke, reside en sus principales rasgos estructurales, que no constituyen una narración en torno a las fases vitales, sino en torno a los espacios y los objetos (2006: 653). Es un texto que, como ningún otro de Benjamin, señala la investigadora, refleja en su proceso de creación la historia de su persecución, exilio y desarraigo (653-654). Además de estas características del libro, la referencialidad a otras obras literarias, tanto propias como de otros autores, entre las cuales destaca En busca del tiempo perdido de Marcel Proust (Lemke, 2016: 656), también podría considerarse como punto de unión entre el texto de Benjamin y el de Obligado, que despunta tanto por su expresión narrativa exquisitamente poetizada como por la sugestión espacial.

En palabras de Antonio Garrido Domínguez, "se pueden distinguir diversos tipos de espacio dentro del espacio literario: único o plural, presentado vagamente o en detalle, espacio sentido o referencial, contemplado o imaginario, protector o agresivo, de la narración y de lo narrado, espacio simbólico, del personaje o del argumento, etc.” (2008: 210). De este modo, el texto consigue representar el espacio infinito de modos diferentes: mediante la mención sucesiva o simultánea de diferentes lugares, a través de la superposición de espacios contrapuestos: "el que en este momento cobija o presiona al personaje y el que en un pasado más o menos lejano fue testigo o causante de su infortunio o felicidad, el espacio que agobia al personaje en el presente y el soñado por éste como promesa de un felicidad futura o, simplemente, para olvidar los rigores del contexto inmediato" (Garrido Gómez, 2013: 213). En este sentido, "Nada útil" es un cuento paradigmático para la pluralidad de espacios recreados en un texto de breve extensión.

El personaje principal de "Nada útil" es Teo, un joven que desde su pueblo se fue con su madre a París para intercambiar manzanas por huevos y un poco de carne. Pero al llegar a 
la plaza, en lugar de los puestos de las vendedoras, se encontraron con soldados, tanques y camiones que se iban llenando de gente. Un policía avanzó hacia su madre y le arrancó la cesta. Y ella, pensando en que su hijo se salvase, le gritó que corriera, que se alejara de la plaza y que no mirara atrás (Obligado, 2015: 73). Después de horas vagabundeando por calles llenas de soldados, Teo encontró un portal abierto y, a través de una ventana con cristales rotos, logró entrar en un piso abandonado (71-72). El cuento, narrado por una voz omnisciente, se inicia con la irrupción de Teo en el piso, por lo que la linealidad del relato se ve interrumpida por las continuas analepsis que desvelan el pasado vivido por Teo en su pueblo, sin especificar cuál, y el día en que llegó con su madre a París. Estas distorsiones temporales posibilitan la compleja elaboración de diferentes espacios: el piso en el que se esconde Teo, la plaza parisina en la que se produce la detención de la madre, el pueblo de Teo. A diferencia de estos lugares que conoce el protagonista, están los espacios intuidos por él. Encerrado entre cuatro paredes, Teo puede adivinar el espacio que le rodea, el portal, los pisos colindantes y la vida en ellos, únicamente gracias a las percepciones olfativas y auditivas. Mientras tanto, la luz que traspasa las cortinas amarillas le permite sentir el exterior inmediato. Por último, la ciudad de París, como parte integrante del espacio global de la colección, cobra un significado especial al analizar la colección de relatos como una totalidad.

Los elementos de cohesión que nos permiten establecer la relación entre "Nada útil" y los demás textos de la colección y detectar el lugar geográfico del presente del cuento son de diferente índole. El piso en el que se esconde Teo es aludido en varios textos. En el cuento "Europa", que precede a "Nada útil", París es el destino de la luna de miel de Héctor Lejárrega y su esposa Leonora, al que se dirigen en el histórico barco de Cap Arcona, donde ella conoce a Gastón, un joven pintor que se convertirá en su amante. Durante este viaje, Héctor compra un piso que no está "ni en L'Étoile, ni en la rive droite, no era Place Vendôme ni la zona de Les Tuilleries sino en un barrio modesto, cerca de Place des Vosges" (63). El libro japonés que Teo encuentra en el piso, Senzbazuru Orikata, del año 1797 y sobre el arte del origami, es el que le regaló Gastón a Leonora y gracias al cual ella, y más tarde Teo, aprende a hacer pajaritas de papel (59), las cuales son a su vez referidas en otros cuentos también. ${ }^{6}$ Asimismo, el olor a un perfume de lilas que cree percibir el joven en el piso y que le hace imaginar a una mujer elegante y hermosa, alusión, por su parte, a Leonora (74), conecta con los cuentos "Un cadáver en la biblioteca", "El cuerpo" y "La peste", en los que también se hace mención a la fragancia de lilas. Las mariposas delineadas con tinta oscura que decoran una habitación del piso (77) son mencionadas por Fernanda, sobrina de Héctor, en "El verdadero amor nunca se olvida", donde recuerda que en el piso parisino de su familia había una cenefa con mariposas un poco siniestra (140). Las mariposas interrelacionan este cuento también con "Europa", en el que se indica que Gastón, en lugar del cuerpo desnudo de Leonora, había pintado una enorme mariposa nocturna (66), y con "Porcelana", en el que un personaje femenino comenta que el artista Gastón de la Plaza pintaba unas mariposas muy turbadoras, supuestamente con sangre (191). ${ }^{7}$ El nombre del barrio en el que está situado el piso, Les Marais, es referido finalmente en "El verdadero amor nunca se olvida" (140) y "Verano" (215). Asimismo, las cortinas amarillas del piso, aludidas en diferentes ocasiones en

\footnotetext{
${ }^{6}$ Las pajaritas blancas aparecen en "Un cadáver en la biblioteca", "El cuerpo", "La peste" y en "Verano".

${ }^{7}$ El "batir de alas de una mariposa contra el cristal de la ventana" (Obligado, 2015: 73) conecta ese cuento con Infancia en Berlín hacia el mil novecientos de Benjamin, en la que el autor rememora su cacería de mariposas.
} 
el relato, también están evocadas en "El verdadero amor nunca se olvida" (140) y "Verano" (215), por lo que queda claro que Teo entró en el piso de los Lejárrega, que "[h]abía estado abandonado durante la guerra" (140). Mediante los elementos unificadores, que nos facilitan determinar con exactitud en qué ciudad y qué barrio y en qué piso está escondido Teo, el espacio de "Nada útil" forma parte del espacio total de la colección, que engloba, tal y como ha sido explicado, diferentes países y continentes a lo largo de décadas. De este modo, el espacio sirve de apoyo para la reflexión de la autora sobre los temas del desarraigo, la extranjería y la frontera, destacando los desplazamientos como rasgo esencial inherente al ser humano y abogando por la descentralización, desterritorialización y excentricidad. En este sentido, el espacio de "Nada útil" es una pieza más en el mosaico que representa el espacio humano en movimiento, el de las migraciones.

\section{El piso parisino y los espacios colindantes}

“Además de un concepto", pone de relieve Antonio Garrido Domínguez, "el espacio narrativo es ante todo una realidad textual, cuyas virtudes dependen en primer término del poder del lenguaje y demás convenciones artísticas" (2008: 208). Las elaboradas construcciones sintácticas y la cuidadosa elección de léxico hacen que la prosa de Clara Obligado despunte por un lirismo de gran poder sugestivo. La poeticidad de su expresión está en cumplimiento con la tarea del poeta, quien, según García Lorca, ha de ser profesor en los cinco sentidos corporales: vista, tacto, oído, olfato y gusto, y para "poder ser dueño de las más bellas imágenes tiene que abrir puertas de comunicación en todos ellos [...]” (García Lorca, 1967: 67). En la descripción del piso en el que está escondido Teo podemos ver esta intercomunicación entre todos los campos sensoriales que construyen este espacio rico en imágenes y en una incesante conexión con los espacios colindantes, como son el exterior inmediato de la casa, la ciudad, el portal, los pisos vecinos, así como con los espacios de la memoria y la imaginación.

La subdivisión de los lugares en grupos compone, afirma Mieke Bal, una forma de aumentar la penetración en las relaciones entre elementos. El contraste entre interior y exterior es pertinente con frecuencia, pudiendo ellos adquirir variados significados, tal y como es la sugerencia de protección o reclusión en el caso de los espacios interiores, o de peligro o libertad en el caso de los espacios exteriores, o también un desarrollo de uno a otro (Bal, 2009: 51). La frontera entre dos lugares, apunta Bal, puede desempeñar un papel especial: "Al igual que en la mitología cristiana el purgatorio actúa de mediador en la oposición entre cielo e infierno, del mismo modo la puerta principal puede connotar una barrera crucial para alguien que pretenda entrar en ciertos círculos" (ibid.: 52). El confín entre dentro y fuera en "Nada útil" connota diferentes significados que se revelan mediante los elementos, entretejidos con variaciones a lo largo del cuento, que sirven de puente entre el interior y el exterior: caños del agua por los que sube Teo al piso y a través de los cuales escapa de él, las ventanas cubiertas de cortinas amarillas o los pocos cristales que no dejan ver el exterior. Los adjetivos, los adverbios y toda clase de frases cuya función sea calificativa constituyen, explica Luz Aurora Pimentel, los instrumentos lingüísticos para dar cuenta de las "propiedades sensibles" que el objeto posee morfológicamente o por atribución (2016: 26). Los objetos "fronterizos" que marcan la separación y la confluencia del interior y el exterior 
en el cuento de Obligado son matizados por medio de referencias sensoriales, en primer lugar visuales. Muy ilustrativas en cuanto a la riqueza léxico-connotativa son las cortinas amarillas, indicadas ya en el primer párrafo (Obligado, 2015: 71), puesto que encarnan la polarización oscuridad/luz que se corresponde con el contraste dentro/fuera, y operan como línea divisoria/unificadora entre dos lugares que adquieren una simbología diversa. Las cortinas casi doradas, de una tela muy liviana, vaporosa, que velaba las ventanas, filtraban una luz ambarina (72-73). Asimismo, "[f]iltrada por las cortinas amarillas, el reverberar de la primavera parecía ejecutar un baile de sombras” (74). Más adelante, un rasgado en las cortinas es el que, tal vez, había permitido que una moneda de sol ardiente le cayera a Teo sobre la cara (75). De los ejemplos se desprende que las cortinas tienen una función vehicular entre el piso y el exterior, siendo la luz que traspasan las cortinas el único contacto visual que tiene Teo con el mundo de fuera. Al contrario, los pocos cristales sin velar, opacos y lechosos, no dejan ver el exterior (72). La percepción del exterior se ve influida por el transcurrir del tiempo, como cuando Teo se da cuenta de que "en el patio de vecinos no solo había una hiedra, la vegetación se había encrespado y el viento del crepúsculo agitaba las pesadas cabezas de los manzanos" (76-77). ${ }^{8}$ Las cortinas le permiten conectarse con el mundo, orientarse temporalmente y desarrollar estrategias de supervivencia al percatarse de la "protección de la hiedra de su casa" (76).

La confrontación de la luz, que viene de fuera, y la oscuridad del piso adquieren diferentes significados. Por un lado, la oscuridad da cobijo a Teo y es cómplice de su secreto, pero, por el otro, le inspira miedo y le hace ver la realidad de forma distorsionada. Así, al quitar las sábanas que cubrían los muebles de la casa, y en la penumbra, los enseres adquirieron formas prehistóricas. Por la oscuridad que iba ganando la sala, los muebles parecían animales agazapados (74). Teo intentó calmarse, temiendo que si no se movía, iba a empezar a temblar (74). El interior, simultáneamente, simboliza tanto un refugio como un peligro. La oscuridad del piso protege a Teo, pero, a la vez, el silencio reinante en él deja al descubierto su presencia y constituye un elemento amenazador.

Los elementos amenazadores son expresados a través de recreaciones auditivas y provienen de la calle, del portal, de otros pisos del edificio y también del propio piso en el que se encuentra el personaje. Los efectos sonoros como sinónimo de peligro son observables ya en el primer párrafo del cuento: "ningún ruido pareció delatar la llegada del intruso" (71). El sonido, decisivo para la seguridad del personaje, es aludido a lo largo del texto de distintas maneras. Teo tuvo que beber del grifo sin hacer ruido, ya que el gorgoteo podría denunciarlo, también ir sin zapatos y avanzar a tientas por el pasillo para volver, más adelante, de puntillas a la habitación donde había caído (72-79). Paralelamente, los sonidos provenientes de la calle también pueden señalar el miedo y el peligro. Asustado por el ruido de botas, de los soldados, el grito de alguien, una carrera, Teo pasó la noche escondido debajo de la cama (75). Del mismo modo, en otra ocasión, una sirena que rompió el filo de la mañana, carreras, portazos, golpes, botas, gritos en alemán, que creía llegarían hasta él, le obligaron a buscar un escondite, rodar bajo el sillón y pegarse al muro (76). Las botas y las voces alejándose son consecuencia de las palabras de alguien que sugirió que no rompieran esa puerta, porque el

\footnotetext{
${ }^{8}$ La frase "La sombra protectora de los manzanos, bajo la que había crecido" (77) comunica el espacio exterior e interior con el de la memoria.
} 
piso estaba vacío, devolvieron el silencio al espacio y con él la frágil y cambiante seguridad. Alusiones a los camiones, las órdenes torvas de los soldados, tanques, ladridos, botas, la detonación de las armas y a los alemanes y la policía francesa, gendarmes (78), gritos en la calle y el subsiguiente miedo de Teo (79) permiten recrear, auditivamente y desde la posición del perseguido, el ambiente de París durante la invasión alemana así como sus secuelas en el personaje.

Los efectos acústicos provenientes de los alrededores del piso completan la configuración del espacio, operando como catalizadores de los sentimientos de Teo y reveladores de su estado psicofísico. Por los ruidos, como lo son las voces de las mujeres, Teo adivina la presencia de los vecinos. Su vida cotidiana forma oposición con la extremidad de la situación en la que está el protagonista, al que un entrechocarse de vajilla le hace crujir el estómago (72). El tarareo de una mujer que dormía a un bebé provoca que algo estalle en la cabeza de Teo, quien se acurruca en una esquina, y abrazado a sus piernas, comienza a sollozar (74). La recreación de los exteriores mediante los sentidos insinuados pueden connotar, además, la libertad encarnada en el trino de los pájaros, el timbre de las bicicletas o el canto agudo de un afilador que escucha el protagonista (74). Sin embargo, predomina el significado de los efectos auditivos como potencialmente peligrosos, y como tales serán decisivos en el desenlace del relato.

Los espacios del cuento se completan con las sensaciones olfativas que aluden al olor a polvo, a laca, a cera del piso que ocupó Teo, a los cestos olorosos que llevaba su madre del campo a la ciudad (72). Las referencias olfativas se amplían con el olor a encierro, a un suave perfume a lilas, al pastel de manzana que alguien estaba preparando en el edificio y con el olor a humedad del libro (74-75). El olor a campo, el aroma de la cosecha que trae una ráfaga de brisa, la alusión una lluvia olorosa de primavera (76-79), completan el universo sensorial agradable sentido por Teo en un espacio limitado que se ensancha y se enriquece con la evocación de los aromas del pasado que configuran el paraíso de la anteguerra. Las percepciones de los olores sirven como estimulantes de las imágenes mentales de Teo. Al creer percibir la fragancia de un perfume de lilas, Teo imaginó a una mujer elegante y hermosa (74), el olor a campo le hizo verse a sí mismo pisoteando con los pies desnudos un charco de pétalos rosados caídos del manzano del patio (76), en una noche de lluvia olorosa de primavera soñó con Marie (79). El olor al pastel de manzana que alguien estaba preparando y la posterior percepción del personaje del atardecer revuelto, de finales de primavera, desencadenaron en Teo pensamientos esperanzadores proyectados hacia el futuro imaginando que pronto vendrá el verano, que el manzano reventará de frutos y que su madre hará dulces y que su casa olería a azúcar (79). A diferencia de los efectos auditivos, que se presentan como amenazantes, los olfativos le generan a Teo visiones que lo conectan con las sensaciones cotidianas y placenteras, pertenecientes a los espacios evocados que representan la seguridad del hogar y la tranquilidad de la inocencia perdida.

\section{El espacio evocado, el espacio imaginado}

La elección de los verbos en el cuento es reveladora en cuanto a la importancia de los espacios evocados e imaginados en el cuento. El verbo "recordar" es utilizado hasta nueve veces, mientras que "imaginar", seis. Los espacios rememorados son la plaza en la que se 
produce la detención de su madre y el pueblo del protagonista; representan dos espacios antagónicos en cuanto a la experiencia del personaje. La escena de la plaza es recordada en diferentes ocasiones en el cuento con el fin de transmitir el impacto que produjo en Teo y las crueldades de la guerra. En el primer párrafo se traen a la memoria los gritos de la madre pidiendo a Teo que corriera y se alejara de la plaza sin mirar atrás (71). En el tercero se amplía la escena con informaciones adicionales sobre su salida del pueblo, la llegada a la plaza, la presencia de los militares y el silencio espeso de la plaza (el efecto auditivo una vez más funciona como elemento amenazador); también se introduce la escena de las manzanas tiradas sobre los adoquines rodando pendiente abajo, con su destello de alegría absurda. El párrafo se cierra con los mencionados gritos de su madre (72-73). Estos gritos de su madre y las manzanas que se persiguen por una pendiente serán recordados también en el cuarto párrafo como señal de la perturbación del protagonista al que todavía le cuesta asumir lo ocurrido (74). Estas referencias anafóricas, esmeradamente distribuidas en el texto, consiguen transmitir el trauma vivido por el personaje.

Otro espacio evocado, el lugar de origen, aparece como el paraíso perdido, idealizado por los recuerdos y situado en un tiempo indefinido. Luz Aurora Pimentel, en su obra El espacio en la ficción, más concretamente en su análisis del valor simbólico del espacio en Pedro Páramo, destaca las características de este tipo de lugares:

Tiempo sin tiempo el del paraíso perdido; mítico porque la imaginación, la nostalgia y el deseo lo han moldeado a su imagen y semejanza; porque han hecho de él un pasado monolítico, absoluto, sin eventos singulares que marquen, de manera irreversible, el devenir; es aquel paraíso perdido un espacio fuera de todo tiempo y toda realidad. Es por ello que entre el entonces de la nostalgia y el presente de la destrucción cumplida sólo puede darse una confrontación total, sin matices: la plenitud ideal frente al vacío de una muerte sin remisión; paraíso frente a infierno. (2016: 155)

Así Teo recuerda su casa, los anaqueles abarrotados de dulces y conservas, el huerto, el pan crujiente y el tazón lleno de leche (Obligado, 2015: 73). La abundancia y el bienestar de aquel entonces se contrastan con la escasez del piso parisino en el que encuentra latas de conservas, arroz, azúcar, pero nada fresco. La sugerida confrontación se corresponde con la de normalidad/peligro o vida/muerte. La memoria de su madre llamándole a desayunar se contrapone a sus gritos de la plaza y al hambre que experimenta en el piso (73). El miedo, la cohibición, el terror dominante en el piso parisino forman oposición con el pueblo y la melena rubia de Marie, su novia, los brazos frescos, su pulso en el cuello, la risa rápida y los dos bañándose en el río (78). El río, como símbolo de libertad, forma oposición con el agua del grifo que Teo no se atreve a abrir. Por un lado, está su recuerdo de cuando se metía en el río hasta lograr atrapar un pez con las manos; por el otro, las voces y los llantos de niños de la calle (80). La ciudad y el pueblo funcionan como espacios diametralmente opuestos a modo del infierno y el paraíso.

El objeto que Teo encuentra y que sirve como punto de inflexión en el cuento es un libro. Al no haber luz, lo conoce a través de las sensaciones táctiles: es áspero, su papel maleable y un poco húmedo pero firme (75). Al pasar la noche, los contornos se hacen visibles, y así, el protagonista puede leer las únicas letras comprensibles del volumen antiguo, un tratado de geometría oriental: Senzbazuru Orikata, Japón, 1797 (75). A la vez, la luz que traspasaba las cortinas amarillas deja reconocer los reflejos ominosos de la noche convertidos 
en jarras y tazas durante el día (75-76). La reconversión de los objetos gracias a la luz hace que el joven imagine el jardín de su casa (76). La luminosidad de las estampas mentales del pasado contrasta con la oscuridad, la incertidumbre, el miedo y el peligro del piso parisino.

El arte del origami le permite a Teo poblar el espacio en el que se encuentra con la fantasía para poder evadirse de la realidad de la guerra. La trasformación del espacio se realiza mediante la matemática y los pliegues, sus manos y su mente vibrando al compás, siguiendo las pautas del libro. De esta manera, el "espacio se dilata y se contrae, el mundo cambia" (77). Para aprender el arte de la papiroflexia, Teo proyecta los diagramas que estudia en el libro en el rectángulo del techo, tirando líneas y dividiendo cuadrados y triángulos una y otra vez, imaginándolos bajo la mirada curiosa de la araña (77). La proyección de su fantasía encima del objeto material, un techo, refleja esta sustitución del espacio "real" con el mentalmente evocado. Asimismo, levantado y visto bajo la luz, el cuadrado papel frustrante, del que solo emergen figuras triviales, "se convierte en una linterna que dibuja los perfiles de una fiesta" (78). En la mente de Teo surgen la música de acordeones, farolitos, nervadura de oro, vestidos con tirante, y la escena, ya mencionada, de él y Marie bañándose en el río (78). El colorido y la musicalidad de las evocaciones contrastan con el silencio y el vacío del piso. $\mathrm{Si}$ al principio del relato se dan referencias al piso, sus habitaciones (dormitorio, salón, habitación de la niña, cocina) o los objetos (mesilla de noche, cajón, cama), conforme pasa más tiempo Teo en el piso se imponen las imágenes de un pasado feliz (que trasladan a un segundo plano los recuerdos de la plaza parisina): lo material pierde peso frente a la evocación.

Después de días intentándolo, Teo consigue crear una pajarita de papel, una grulla, con el piquito doblado y las alas majestuosas que se agitan, si se le tira de la cola (77). Las alas de papel y su movimiento crean oposición a las restricciones que sufre Teo en su encierro. El cromatismo de las pajaritas también da la sensación de un tímido dinamismo dentro del espacio del piso. En busca de más papel, Teo descubre que los anaqueles de la cocina están forrados con un pliego azul satinado con el que hace pajaritas de colores que se suman a las pajaritas color lenteja (78). Por primera vez, la noche no se presenta amenazadora. Las pajaritas han convertido el piso en un lugar menos hostil que estimula imágenes placenteras (78).

El final del libro descubre que la fantasía y la creatividad, expresadas a través de elementos cromáticos, consiguen la evasión de la realidad que a su vez sirve de aliciente para la supervivencia. Preso por las ansias de producir más pajaritas coloridas, de conseguir más papel, Teo empieza a hacer pajaritas del papel del libro. Lo que ocurre después es una sucesión vertiginosa de pensamientos y acciones que se potencian con construcciones paralelísticas y anafóricas (81). Los elementos auditivos se intensifican: un tiro en la calle, o una voz demasiado alta, las botas y los gritos que suben, los ladridos, el grito de un vecino delatando que hay alguien en el piso, que ha escuchado correr el agua, el comentario que seguro es un judío (81) se corresponden con el peligro al que está expuesto el protagonista y con su estado emocional dominado por la angustia. Como oposición, los colores aludidos revelan la clave de lectura del cuento. Las pajaritas que vuelan y se arremolinan en el aire encerrado embelesan al soldado que abrió la puerta del piso permitiendo que Teo corra hacia la ventana, atraviese las cortinas amarillas, y sujetándose en la hiedra de la casa, baje por la cañería -todos ellos elementos mediadores entre el espacio cerrado y el abierto-, salte al patio 
de vecinos, a la puerta abierta de la calle por donde logra ver, por fin libre, el jardín de las manzanas (81). Así, el título "Nada útil", insinuado a lo largo del cuento ${ }^{9}$ - Teo recuerda que su madre le critica que no sabe hacer nada útil (73) y cree oír el reproche de ella de que sus monigotes de papel no tienen sentido (80) - obtiene un significado revelador, al adquirir las pajaritas "inútiles" su utilidad en el camino del protagonista hacia su libertad. De este modo, se reafirma la idea sobre la fuerza mental como generadora y recreadora de infinitos espacios, construidos a base de la imaginación, como oposición, protectora y reconfortante, a la realidad espacial de restricciones, peligros y miedos vivida por el protagonista. La extraordinaria sensibilidad poética de Clara Obligado, la capacidad evocadora de sus expresiones y su convicción narrativa hacen que los espacios de este cuento sean lugares vibrantes de sensorialidad y significados, recreados con los cinco sentidos, logrando así nuevos simbolismos y dimensiones.

Tanto en el cuento "Nada útil" como en la colección La muerte juega a los dados se aprecia la omnipresente intercomunicación entre diferentes elementos que pueden referirse a las obras literarias, los hechos históricos, vivencias de los personajes, a los objetos que habitan el espacio, los aromas que desprenden y las imágenes que evocan. De este modo se construye un espacio común, compartido entre diferentes protagonistas y en distintas épocas. La negación de la frontera, reiteradamente señalada en las entrevistas y en la obra narrativa de Clara Obligado, se elabora en el cuento analizado también mediante cierta dilución de los límites entre el espacio exterior y el interior. Estos dos espacios dialogan a través de los objetos "fronterizos" que sostienen la idea de un espacio que solamente puede cobrar el sentido completo percibido o intuido en su totalidad y en la interrelación de diversas componentes. Asimismo, los espacios del presente y los del pasado, los vividos realmente y los imaginados confluyen unidos por las referencias visuales, táctiles, olfativas, auditivas y gustativas que desempeñan variadas funciones en el cuento. Mientras que los sonidos venidos de fuera sugieren el peligro y el miedo del protagonista ante él, los olores agradables de la naturaleza o de la comida suponen la vuelta mental al espacio feliz de su pueblo como una especie de paraíso perdido. Las oscilaciones entre las luces y las sombras desvelan el estado emocional de Teo en la situación límite de la que logra salir gracias a la belleza, el arte y la fuerza de la imaginación, que a su vez constituyen los pilares de la sutil y sugestiva prosa de Clara Obligado.

\section{Bibliografía}

ABDALA, Verónica: "Entrevista. Clara Obligado: «Aceptar la tortura y la muerte es perder toda la categoría moral»". Clarín, 13/8/2016, https://www.clarin.com/cultura/claraobligado-aceptar-tortura-categoria_0_BJOaynoF.html (15/10/2017).

ANDERSON IMBERT, Enrique (2007): Teoría y técnica del cuento. Barcelona: Ariel.

BAL, Mieke (2009): Teoría de la narrativa (una introducción a la narratología). Madrid: Cátedra.

\footnotetext{
${ }^{9}$ También en el cuento "Un cadáver en la biblioteca", Leonora, que hace una pajarita de papel a su hija Alma, asegura que para tener suerte hay que hacer mil y que las cosas bellas nunca sirven para nada. Sin embargo, en el cajón de su tocador, junto al perfume de lilas, Alma ve un nido de las pajaritas blancas. Antes el estupor de su hija al ver tantas pajaritas y su exclamación “¡cuántas hay!”, Leonora dice: “-Nunca las suficientes” (15).
} 
BENJAMIN, Walter (2015): Infancia en Berlín hacia el mil novecientos. Madrid, Abada Editores.

CABALLERO, Marta: "Clara Obligado: «Ahora me siento dueña de la forma»". El Mundo, 25/2/2015, http://www.elmundo.es/cultura/2015/02/25/54ec760822601dfa408b4581.html $(10 / 05 / 2108)$.

CASTRO, Pilar: "Petrarca para viajeros. Clara Obligado". El Cultural, 18/3/2016, https://www.elcultural.com/revista/letras/Petrarca-para-viajeros/37786 (10/09/2018).

GARCÍA LORCA, Federico (1967): "La imagen poética de Don Luis de Góngora”. Obras completas. Madrid, Aguilar: 62-85.

GARRIDO DOMÍNGUEZ, Antonio (2007): El texto narrativo. Madrid, Editorial Síntesis.

GOMES, Miguel: "Para una teoría del ciclo de cuentos hispanoamericano". RILCE: Revista de Filología Hispánica XVI/3 (2000): 557-583.

LEMKE, Anja (2006): “Berliner Kindheit um neuzehnhundert”. Benjamin Handbuch. LebenWerk-Wirkung. Ed. Burkhardt Linder. Stuttgart, J.B. Metzlersche Verlagsbuchhandlung und Carl Ernst Poeschel Verlag: 653-663. DOI: https://doi.org/10.1007/978-3-476-98691-7

LORENZÓN, Claudia: "Cada vez que se traza una frontera detrás viene una guerra o una exclusión". Télam, Agencia Nacional de Noticias, 6/8/2016, http://www.telam.com.ar/notas/201608/158033-clara-obligado-se-traza-una-fronteradetras-viene-guerra-o-exclusion.html (06/08/2016).

MORA, Gabriela: "Notas teóricas en torno a las colecciones de cuentos integrados (a veces cíclicos)". Revista Chilena de Literatura 42 (1993): 131-137.

NOGUEROL JIMÉNEZ, Francisca (2008): “«Juntos, pero no revueltos»: la colección de cuentos integrados en las literaturas hispánicas”. Alma América: in honorem Victorino Polo II. Coord. Vicente Cervera Salinas y María Dolores Adsuar Fernández. Murcia, Universidad de Murcia: 162-172.

OBLIGADO, Clara (2005): Las otras vidas. Madrid, Páginas de Espuma.

--- (2011): El libro de los viajes equivocados. Madrid, Páginas de Espuma.

--- (2015): La muerte juega a los dados. Madrid, Páginas de Espuma.

PIMENTEL, Luz Aurora (2016): Espacio en la ficción. México, Siglo XXI Editores.

SÁNCHEZ CARBÓ, José Adalberto (2009): Rincones del mundo. La función del espacio en las colecciones de relatos integrados en México. Tesis Doctoral. Salamanca, Universidad de Salamanca.

TOMASSINI, Graciela: "La frontera móvil: las series de cuentos «que se leen como novelas»". El Cuento en Red 9 (primavera 2004): http://cuentoenred.org (15/03/2018). DOI: http://dx.doi.org/10.18441/ibam.4.2004.16.49-65

VALCÁRCEL, Carmen: "Los cuentos de Clara Obligado: la escritura excéntrica". Versants. Revista Suiza de Literaturas Románicas LXII/3 (2015): 93-106. DOI: http://doi.org/10.5169/seals-587535 
(C) Maja Zovko

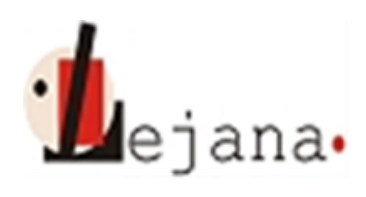

http://ojs.elte.hu/index.php/lejana

Universidad Eötvös Loránd, Departamento de Español, 1088 Budapest, Múzeum krt. 4/C 